before the idea of evolution was accepted, mycologists had recognized circles of affinity within the fungi. Evolution cannot be both the key to the problem and also the lock. A study of phylogeny may indicate what forms are primitive, and these are probably the simplest. But the evolutionary history of the higher fungi is still a mystery. A study of fairy rings suggests that the mycelium is much more important in reproduction than is the spore, and yet we have elaborate and extremely fertile fruit bodies.

Microscopic characters are of great significance in dealing with species, and hyphæ, as in the strands of Merulius lacrymans, may show much diversity of structure; they may have taxonomic significance. Biological characters must not be stressed too much. For example, the predacious fungi show a general and similar pattern of behaviour, but the predacious habit is to be found among Phycomycetes, Basidiomycetes and Hyphomycetes.

B. BARNES

\section{ASH AND CLINKER IN INDUSTRY}

\section{BY T. F. HURLEY, O.B.E.}

Fuel Research Station, London, S.E.10

$\mathrm{D}$ URING October 28-29, a conference described as "A. Special Study of Clinker and Ash in Industry" was held by the Institute of Fuel at the Institution of Mechanical Engineers. Twelve papers were discussed which eovered the origin and nature of the mineral matter in coal ; its laboratory examination; the extent to which it is responsible for atmospheric pollution; the methods by which it can be removed either from the coal itself or from the products of combustion; and its effect upon the utilization of coal in various types of industrial plant. The papers had been published in advance in the Journal of the Institute of Fuel, and the Institute hopes to publish the text of the papers and discussions in the near future (£1 $1 s$.).

In the field of utilization, small industrial boilers, gas producers, steel works plant, and, looking ahead, the industrial coal-fired gas turbine were considered, but most attention was devoted to the large watertube boilers used by the British Electricity Authority, which is the largest single user of coal. This one organization now consumes 35 million tons of coal per annum, and as the average ash content of the rough slack supplied to it is about 15 per cent, it has to deal with about 5 million tons of ash per annum. Merely to handle this quantity of waste material is a formidable task, but during recent years the problems associated with ash and clinker have been further increased as a result of the present tendency to generate electricity in mammoth power stations employing very large and costly boilers working at extremely high temperatures and pressures. Among other consequences, the size of the stations requires more elaborate and expensive plant to avoid excessive atmospheric pollution in their vicinity, the higher temperatures in the boilers lead to a more objectionable type of deposit upon the heating surfaces, and to take one of a small number of very large boilers off the line for cleaning out of its turn affects materially both the output of the station and the cost of the electricity generated.

Taking industry as a whole, the importance of ash is steadily increasing as a result of changing mining conditions, which have led to more and more mineral matter being included in the coal brought to the surface. Various reasons were given at the Conference, the chief of which were, first, that the better seams have been worked out and those now being mined not only contain more ash but also include more dirt bands ; and, secondly, increased mechanization causes more dirt to be mined and at the same time reduces the quantity which can be removed from the coal underground. Excluding 'free dirt', British coal seams still contain on the average only 5.5 per cent of ash and probably compare favourably in this respect with those of other major coalproducing countries; but for the reasons given, run-of-mine coal now includes on the average about 15 per cent of free dirt. This represented about 33 million tons of the 'raised and weighed' output for 1950.

It is obvious that the cost of mining dirt and bringing it to the surface is comparable with that of winning coal; but no suggestion was made at the Conference that the quantity of dirt brought to the surface could, or should, be reduced. In fact, a future increase in the ash content of coal was accepted as natural and inevitable.

Ash costs just as much as coal to convey from the pit head to the point of utilization, and at each stage beyond that it is a costly nuisance. Again taking modern power station practice as an example, ash costs more to pulverize than coal and it causes more wear in the machinery; it affects adversely the efficiency of combustion; it requires the size and therefore the capital cost of the boilers to be larger and at the same time it increases the difficulties of design and operation; it necessitates the provision of ash-handling equipment comparable in size and cost with the boilers themselves; some of it forms objectionable deposits which reduce both the efficiency and the availability of the boiler; it requires the installation of expensive dust collectors to minimize atmospheric pollution and, even when it has been collected, its disposal is a major difficulty.

Many, but not all, of these effects can be reduced materially by using known methods of cleaning the coal at the pit, but this involves a high cost in capital equipment, power and labour. So recently as 1950 the National Coal Board asked in its annual report whether "it may sometimes not be more economical to save some or all the cost of coal preparation at the price of reduced efficiency in the final stage of conversion". To this question the National Coal Board itself now appears to provide its own answer by stating that when all the cleaning plants ordered between vesting date and the end of 1951 are in operation, they will deal with about $42 \frac{1}{2}$ million tons of coal per annum. More than 100 million tons of coal are already cleaned mechanically each year.

On the other hand, the Conference showed that there is considerable divergence of opinion with regard to the extent to which it is economical to wash coal instead of dealing with the ash during utilization. This lack of agreement may arise from the wide variations which occur in the chemical composition of the mineral matter in coal and in the manner in which it is associated with the coal substance. Both the ease with which coal can be cleaned and the influence exerted by a given quantity of ash upon different industrial processes are affected by these variations.

Most coal-cleaning processes are based upon the difference between the specific gravities of coal and dirt, and some are capable of making a close 'cut' at 
any predetermined density. When, therefore, the material to be cleaned consists partly of coal particles containing little dirt and partly of dirt particles containing little coal, it is easy to separate it into 'clean' coal and 'pure' dirt. On the other hand, when the coal substance is 'intergrown' with mineral matter, the yield consists of three fractions : relatively clean coal, middlings and dirt. The washery manager then has to balance the overall cost of cleaning against the requirements of his market and to decide what proportion of ash he should allow to appear in each fraction--a task requiring great skill and experience.

With these broad principles in mind, the general opinion of the Conference appeared to be that in present circumstances the more easily cleaned coals should be washed, and the dirty coals, middlings and even the refuse should be burned in the colliery boilers or in power stations erected in the vicinity. Plant is already being installed to burn what would formerly have been regarded as waste material.

The quantity of ash in the coal most easily supplied to a particular industrial plant may well determine the type of combustion appliance to be employed. Thus a chain-grate stoker would not usually be used with coal containing more than about 15 per cent of ash, whereas pulverized fuel containing more than 25 per cent of ash can be used in large boilers. On the other hand, it is very difficult to collect and dispose of the large quantity of fine ash made from pulverized fuel.

The composition of the ash has an equally important bearing upon the type of equipment to be used. Thus, boilers fired with pulverized fuel are usually immune from troublesome bonded deposits ; but severe deposits frequently occur in boilers fired with mechanical stokers when the coal contains relatively small quantities of chlorine (more than 0.3 per cent), sulphur (more than I.8 per cent) or phosphorus (more than 0.03 per cent).
In the same way, the amount of iron in the ash influences its tendency to fuse and form clinker or slag in the furnace. In most cases this is a source of trouble; but in some modern designs the ash is fused deliberately to enable it to be disposed of more easily.

For control purposes, it is obviously desirable to be able to predict the clinkering properties of an ash by a preliminary laboratory examination; but this is rendered difficult by the fact that when the mineral matter in coal is heated it changes its composition in a manner depending on the conditions of heating. In addition, the distribution of its constituents in a finely divided laboratory sample is different from that in the original lump coal. It is, therefore, impossible to devise one laboratory test for ash fusion temperature which would simulate all industrial conditions, and it is not surprising that varying opinions were expressed as to the practical value of ash-fusion temperatures determined by the standard method, which is necessarily empirical.

In spite of the variable nature of ash and its varying importance when coal is burned in industrial plant, it is clear that, if fuel is to be marketed on a national scale, a fair price can be assigned to any particular coal only after a quantitative allowance has been made for its ash content. Karious methods of doing so were described, but every paper read could be used to illustrate the difficulty of devising a universal formula to meet all cases.

In general, the Conference showed that practical means have been found for dealing with the industrial problems associated with the presence of mineral matter in coal and that considerable knowledge is available concerning its nature and its behaviour in industrial plant. Nevertheless, the difficulties caused by it tend to increase, rather than to decrease, and there can be little doubt that they will continue to present major problems so long as coal is used as a fuel.

\section{NEWS and VIEWS}

Mineralogy at the British Museum (Natural History): Dr. W. Campbell Smith, C.B.E.

Dr. Walter CAMpbetr Smith retired at the end of November from the post of keeper of minerals at the British Museum (Natural History) after fortytwo years service. Joining the staff of the Department of Mineralogy in 1910, he became deputy keeper in 1931 and succeeded to the keepership in 1937. He was mainly instrumental in the expansion of the rock collections and in applying modern optical techniques to their identification and nomenclature. His wellknown guide to the Museum's rock collections and his arrangement and labelling of them in the Mineral Gallery are models of clarity and accuracy, objectives no less difficult to achieve in petrology than in other sciences. Dr. Campbell Smith's numerous publications have included studies both in petrology and mineralogy, notably his pioneer investigations on hybridism in igneous rocks, his contributions on the petrology of rocks collected on famous expeditions such as the British Antarctic (Terra Nova) 1910, and his descriptions of new minerals from the manganese mine at Benallt, North Wales. He served as president of Section C (Geology) of the British Association in 1950 , and on that occasion presented a survey of knowledge on the stony meteorites. During his keepership he was promoted to the post of deputy chief scientific officer (1948), and as deputy director of the Natural History Museum he found further scope for his interests in natural history. The knowledge that Dr. Campbell Smith will be able to continue his researches in his chosen field after his retirement will give much pleasure to his numerous colleagues and friends, both at home and abroad.

Dr. F. A. Bannister

Dr. Frederick Auran Bannister, who succeeded Dr. Campbell Smith on December 1, joined the British Museum (Natural History) staff on September 1,1927 , filling the vacancy caused by E. D. Mountain's appointment as lecturer at Grahamstown, South Africa. Dr. Bannister went from the Whitgift School, Croydon, to Clare College, Cambridge, in 1920. He won a Goldsmith Exhibition in 1921 and was placed in the first elass in both parts of the Natural Sciences Tripos, studying physics under Rutherford and mineralogy under Hutchinson. After a year of research work under the direction of Sir Edward Appleton in the Cavendish Laboratory, Cambridge, he joined the Western Electric Co. in 1924, an experience which stood him in good stead in his later 